\title{
The Effects of Antipsychotic Medications on Emotion Perception in Patients with Chronic Schizophrenia in the CATIE Trial
}

\author{
David L. Penn, Ph.D. ${ }^{*}$ Richard S. E. Keefe, Ph.D., Sonia M. Davis, Dr.P.H., Piper S. Meyer, \\ Ph.D., Diana O. Perkins, M.D., Diane Losardo, B.S., and Jeffrey A. Lieberman, M.D. \\ University of North Carolina-Chapel Hill, Department of Psychology, Davie Hall, CB\#3270, Chapel \\ Hill, NC 27599 USA
}

\section{Introduction}

Social cognition has been described as the "mental operations underlying social interactions, which include the human ability and capacity to perceive the intentions and dispositions of others" (Brothers 1990). Adolphs (2001) identified social cognition as "the ability to construct representations of the relation between oneself and others and to use those representations flexibly to guide social behavior." These definitions suggest that social cognition is a set of related processes applied to the recognition, understanding, accurate processing, and effective use of social cues and information in social situations (Penn et al. 1997).

A key aspect of social cognition is emotion perception. Reviews indicate that individuals with schizophrenia have deficits in emotion perception relative to non-clinical controls (e.g.,

\footnotetext{
*Correspondence should be addressed to: David L. Penn, Ph.D., University of North Carolina-Chapel Hill, Department of Psychology, Davie Hall, CB\#3270, Chapel Hill, NC 27599-3270; dpenn@email.unc.edu, telephone: (919) 843-7524, fax: (919) 962-2537.

Contributors

Dr. Penn consulted on the inclusion of the FEDT into the study design, interpreted results, and drafted and edited the manuscript. Dr. Keefe was a co-investigator of the CATIE trial, developed the neurocognitive battery, participated in the design of the research, interpreted the results, and edited the manuscript.

Dr. Davis was a co-investigator of the CATIE trial, participated in the design of the research, designed the statistical analyses, conducted statistical analyses, interpreted results, and edited the manuscript.

Dr. Meyer contributed to the analysis of the data and writing of the writing of the report and edited the manuscript.

Dr. Perkins was a co-investigator of the CATIE trial, participated in the design of the research and the writing of the report.

Ms. Losardo contributed to the analysis and interpretation of the data and writing of the report.

Dr. Lieberman was the principal investigator of the CATIE trail, contributed to the design of the research, and the development of the manuscript.

\section{Conflict of Interest}

Dr. Meyer and Ms. Losardo report no competing interests. Dr. Penn reports having received research funding, consulting fees, advisory board payments, lecture or educational fees from Bristol-Myers Squib, Eli Lilly, Janssen, Johnson and Johnson, and Repligen. Dr. Keefe reports having received research funding, consulting fees, advisory board payments, lecture or educational fees from Abbott, AstraZeneca, Acadia, Bristol-Myers Squibb, Cephalon, Cortex, Cyberonics, Dainippon Sumitomo Pharma, Eli Lilly, Gabriel Pharmaceuticals, GlaxoSmithKline, Johnson and Johnson, Lundbeck/Solvay/Wyeth, Memory Pharmaceuticals, Merck, Orexigen, Otsuka, Pfizer, Saegis, Sanofi/Aventis, and Xenoport; he also receives royalties on the Brief Assessment of Cognition (BACS) and MATRICS Battery (BACS Symbol Coding); in addition, he has a personal stake in the CATIE Project as the Director of the Neurocognitive Assessment Unit and MATRICS as a member of the Neurocognitive Committee. Dr. Perkins reports having received research funding from AstraZeneca Pharmaceuticals LP, Bristol-Myers Squibb, Otsuka Pharmaceutical Co. Ltd, Eli Lilly and Co., Janssen Pharmaceutica Products, and Pfizer Inc.; and consulting and educational fees from AstraZeneca Pharmaceuticals LP, Bristol-Myers Squibb, Eli Lilly and Co., Janssen Pharmaceuticals, GlaxoSmithKline, Forest Labs, Pfizer Inc and Shire. Dr. Davis is an employee of Quintiles. Dr. Lieberman reports having received research funding or consulting or educational fees from AstraZeneca, Bristol-Myers Squibb, Eli Lilly, Forest, GlaxoSmithKline, Janssen, Novartis, Pfizer, and Solvay.
}

Publisher's Disclaimer: This is a PDF file of an unedited manuscript that has been accepted for publication. As a service to our customers we are providing this early version of the manuscript. The manuscript will undergo copyediting, typesetting, and review of the resulting proof before it is published in its final citable form. Please note that during the production process errors may be discovered which could affect the content, and all legal disclaimers that apply to the journal pertain. 
Edwards et al. 2002; Hellewell et al. 1998; Kohler and Brennan 2004; Mandal et al. 1998) with these impairments being related to functional outcomes (Couture et al. 2006). Thus, emotion perception might be an important treatment target, as improvement in emotion perception might result in subsequent improvement in functional outcomes.

Pharmacological intervention studies on social cognition have been rather limited. Littrell et al. (2004) and Kee et al. (1998) found that olanzapine and risperidone, respectively, was associated with improved social perception relative to conventional antipsychotic medication. However, both studies suffer from signfiicant limitations. First, sample sizes were small, particularly for Kee et al.(N=18). And second, Littrell et al. (2004) did not utilize random assignment. In another pilot study, Herbener et al. (2005) found that antipsychotic medications did not improve emotion perception in 13 individuals with first episode psychosis. Harvey et al. (2006) found that neither quetiapine nor risperidone resulted in improved emotion perception among 289 individuals with schizophrenia. Sergi et al (2007) found that neither risperidone, olanzapine, or haloperidol improved emotion perception among 100 oupatients with schizophrenia or schizoaffective disorder. Since Harvey et al. (2006) and Sergi et al (2007) were the only adequately powered studies, it is difficult to draw any confident conclusions regarding antipsychotic medication effects on emotion perception based on previous research. Furthermore, only Sergi et al. (2007) has examined the impact of multiple atypical medications compared to a typical antipsychotic in a large, stable, chronically ill population with schizophrenia.

The National Institute of Mental Health (NIMH) sponsored Clinical Antipsychotic Trials of Intervention Effectiveness (CATIE) trial included a measure of emotion perception in the design (Stroup et al. 2003): This led to the formulation of two research questions. First, would there be significant differences among olanzapine, perphenazine, quetiapine, risperidone, and ziprasidone in improvement in emotion perception as measured by the Face Emotion Discrimination Test (FEDT)(Kerr and Neale 1993) from baseline to two months? And second, which baseline variables predict improvement in emotion perception over two months?

\section{Methods}

\subsection{Study Setting and Design}

The CATIE study was conducted from January 2001 until December 2004 at 57 U.S. clinical sites, including 16 university clinics, 10 state mental health agencies, seven VA Medical Centers, six private nonprofit agencies, four independent practice sites, and 14 mixed system sites. A complete description of study rationale, design, and methods has been previously documented (Davis et al. 2003; Keefe et al. 2003; Lieberman et al. 2005; Stroup et al. 2003). Patients were randomly assigned under double blind conditions to one of five medications: olanzapine, perphenazine, quetiapine, risperidone, or ziprasidone (Lieberman et al. 2005). They were followed for up to 18 months or until treatment was discontinued for any reason (phase 1).

The inferential analyses in this report are limited to the results from phase 1 because of the expectation that most of the treatment effects should occur within the first 2 months of treatment. The CATIE Neurocognition Advisory Group reviewed the literature available at the time the cognition analyses were performed and determined that the majority of cognitive improvement with antipsychotic treatment takes place in the first 2 months of treatment (including that for emotion perception, which was part of the neurocognitive battery). This was largely confirmed by the neurocognitive findings from the CATIE study (Keefe et al. 2007a). 


\section{Participants}

2.2 Subjects-Eligible patients were 18 to 65 years of age; had received a diagnosis of schizophrenia, as determined on the basis of the Structured Clinical Interview of the Diagnostic and Statistical Manual of Mental Disorders, fourth edition; and were able to take oral antipsychotic medication. 1493 patients with a diagnosis of schizophrenia, confirmed by the SCID (First et al. 1994), were entered into the study from 57 institutions. Patients were excluded if they had diagnosis of schizoaffective disorder, mental retardation or other cognitive disorders; had a history of serious adverse reactions to the proposed treatments; had had only one schizophrenia episode; had a history of treatment resistance, defined by persistence of severe symptoms despite adequate trials of one of the proposed treatments or prior treatment with clozapine (see Lieberman et al., (2005) for how this was defined); were pregnant or were breast-feeding; or had a serious and unstable medical condition. There were no exclusion criteria based upon symptoms.

The institutional review board approved this study at each site. Also, written informed consent was obtained from the patients or their legal guardians at each site.

\section{Interventions}

2.3 Treatment-Identical-appearing capsules contained olanzapine (Zyprexa, Eli Lilly) (7.5 $\mathrm{mg}$ ), quetiapine (Seroquel, AstraZeneca) $(200 \mathrm{mg}$ ), risperidone (Risperdal, Janssen

Pharmaceutica) (1.5 mg), or perphenazine (Trilafon, Schering-Plough) (8 mg) or (after January 2002) ziprasidone (Geodon, Pfizer) $(40 \mathrm{mg}$ ). The packaging was done by Quintiles. The dose of the medications was flexible, ranging from one to four capsules daily, based upon the study doctor's judgment. Relative tablet strength was reviewed by senior representatives from each drug manufacturer. Overlap in the administration of the antipsychotic agents that patients received before study entry was permitted for the first four weeks after randomization to allow a gradual transition to study medication. Concomitant medications were permitted throughout the trial, except for additional antipsychotic agents. Patients had monthly visits with study doctors.

Because of product labeling, quetiapine or ziprasidone were given twice daily and olanzapine, perphenazine, and risperidone once daily. To protect blinding, half the patients randomly assigned to perphenazine, olanzapine, and risperidone were assigned to twice-daily dosing and half to once-daily dosing. To minimize initial side effects, patients assigned to quetiapine began treatment by receiving one 100-mg capsule on days 1 and 2 , one twice daily on day 3 , and one for the first dose of day 4 . All patients assigned to twice daily dosing received five identicalappearing capsules to begin treatment. Patients with current tardive dyskinesia based on Schooler-Kane criteria were randomized to treatments other than perphenazine.

2.4 Primary Outcome Measure-The FEDT is comprised of 30 pairs of faces presented concurrently with no time limit, and requires the participant to determine if the two faces in each pair are displaying the same or different emotions (Kerr and Neale 1993). It is a widely used measure of emotion perception with sound psychometric properties (Penn et al. 2006). We selected an emotion discrimination rather than identification task because the latter task is partially mediated by verbal functioning, and our battery already had verbal memory, verbal fluency, and verbal working memory tasks. Thus, we wanted to utilize a social cognition task that was less influenced by verbal processes. A commonly used method for administering the FEDT is via videotape. However, since this method may have been too difficult to implement at a 57-site study, laminated printouts of the faces were used instead. Performance on the FEDT was indexed as the total number of correct responses. 
2.5 Statistical Analysis-For consistency with other CATIE publications, the statistical analyses conducted in this study were similar to those conducted on neurocognition from the CATIE trial (Keefe et al. 2007a). Our goal was to compare the groups on the change in FEDT scores from baseline to month 2. our primary analyses compared treatment groups on FEDT change scores from baseline to month 2 using analysis of covariance (ANCOVA), controlling for baseline FEDT performance; whether the patient had required crisis stabilization in the 3 months prior to study entry defined as exacerbation status, and TD status except where not applicable, as described below. Crisis stabilization was designated a priori as a potentially important covariate in the CATIE protocol and it was included in the current analyses so as to examine whether clinical state at entry could influence changes in social cognition (as well as to be consistent with the original CATIE protocol). This analysis allowed us to examine whether the change for each treatment significantly differed from zero (essentially testing a time effect within each treatment).

The FEDT scores had a ceiling effect and negative skew (Keefe et al. 2006) (See Table one). However, the change-score (FEDT 2-month scores minus FEDT baseline scores), the dependent variable, had an approximately normal distribution, with the scores being symmetrical.

Since patients with TD were not randomized to perphenazine, all analyses containing perphenazine were limited to the cohort of patients without TD. Also, since ziprasidone was added to the trial after $40 \%$ of the patients were randomized, all analyses containing ziprasidone involved a subset of the total sample. Treatment group comparisons were therefore conducted on four analytic data sets with overlapping membership based on the TD and ziprasidone cohort stratification. Each data set only included subjects who had an equal chance of randomization to the treatments under comparison. Perphenazine subjects, in particular, were only compared to equivalent subjects who did not have TD at baseline, and ziprasidone subjects were only compared to subjects who were enrolled after ziprasidone was added.

Using this ANCOVA model, we evaluated the overall statistical significance between perphenazine, olanzapine, quetiapine, and risperidone, excluding patients with $\mathrm{TD}$, relative to $\mathrm{p}=.05$ (i.e., Data Set I). If the overall test was statistically significant, perphenazine was then compared with each of the atypical antipsychotics using a Hochberg modification of the Bonferroni correction for multiple treatment comparisons. Specifically, the largest p-value was compared to 0.05 and the smallest $p$-value was compared to $.05 / 3=0.017$. We then compared the three atypical drugs (olanzapine, quetiapine, and risperidone), including patients with TD, relative to $\mathrm{p}=.05$ (i.e., Data Set II). TD was included as an additional covariate and we also checked for a TD by treatment interaction. Pair-wise comparisons were evaluated only if the overall treatment $\mathrm{p}$-value was $\leq .05$. In the third analysis, we compared ziprasidone and perphenazine, using the subset of patients enrolled after ziprasidone was added and excluding patients with TD, relative to $\mathrm{p}=.05$ (i.e., Data Set III). Finally, we compared ziprasidone with olanzapine, quetiapine, and risperidone, using the subset of patients enrolled after ziprasidone was added and including patients with TD (Dataset IV). Ziprasidone was compared versus the other four treatments in Data Sets III and IV using a Hochberg adjustment in which the smallest $\mathrm{p}$ value was compared relative to $0.05 / 4=0.0125$.

Potential baseline covariates were identified a priori by reviewing previous research on social cognition in schizophrenia (Penn et al. 1997). These covariates included gender, years of education, years since first prescribed an antipsychotic medication, alcohol status, neurocognitive composite score, reading subset of the WRAT, Quality of Life (QOL) Interpersonal Relations Scale, and the PANSS positive and negative scales. The neurocognitive composite score was calculated by creating a z-score of the average of five standardized domain scores (i.e., processing speed, reasoning, working memory, verbal memory, and vigilance). 
An ANCOVA model was computed including these covariates simultaneously, as well as investigator site, pooled into 6 groups based on site care setting, and exacerbation status, and served to determine predictors of emotion perception improvement on the FEDT.

\section{Results}

\subsection{Characteristics and dispositions of patients}

There were 1460 randomized patients available for analysis (Lieberman et al. 2005). The primary cohort for this report consisted of 873 patients who completed the FEDT immediately prior to randomization and 2 months post-baseline. Twenty five percent of these patients were antipsychotic free at baseline, while $60 \%$ reported being on a second generation antipsychotic, and $15 \%$ were on a first generation antipsychotic.

Table 1 summarizes the demographic and clinical characteristics of patients who completed the FEDT at baseline and at 2 months $(\mathrm{N}=873)$, and those who only completed the baseline assessment $(\mathrm{N}=515)$. Participants tested at baseline and month 2 were older, less symptomatic, more likely to be taking olanzapine monotherapy or risperidone monotherapy or any type of antipsychotic treatment at baseline than patients who only completed the FEDT at baseline. Participants with 2 month FEDT data were compared across treatment groups and no major differences were found for the important covariates.

\subsection{Primary analyses: Face emotion test changes after $\mathbf{2}$ months of treatment}

Table 2 and Figure 1 present mean and standard deviation FETD change from baseline to 2 months across the 4 analysis datasets. A one-way ANCOVA for patients without TD revealed that there was no overall significant difference among the 4 treatment groups $\mathrm{F}=.30(\mathrm{p}=.82)$, (Data Set I). In examining individual treatment changes, the perphenazine FEDT ANCOVA least-square mean change score was $.54(\mathrm{p}=.01)$. Least-square mean change scores observed for the quetiapine, $.36,(\mathrm{p}=.09)$, risperidone, $.35(\mathrm{p}=.09)$ and olanzapine, $0.27(\mathrm{p}=.19)$ groups were not significantly different than zero (Data Set I).

We then included patients with TD in the analyses to compare the three atypical antipsychotic groups (Data Set II). There was no overall difference in FEDT change among the treatment groups $(\mathrm{p}=.99)$. The magnitude of change among the groups was very similar to the analyses from Data Set I. None of the three groups showed a FEDT least square mean change score significantly different than zero (olanzapine, $0.35(\mathrm{p}=.053)$, quetiapine, $0.34(\mathrm{p}=.07)$, and risperidone, $0.32(\mathrm{p}=0.09)$. There was no difference in FEDT change scores between TD and non TD patients within Data Set $2(\mathrm{t}=.90, \mathrm{p}=.37)$, and no TD by treatment group interaction $(\mathrm{p}=.99)$.

Change in the FEDT from baseline to 2 months was examined in the perphenazine and ziprasidone groups excluding patients with TD (Data Set III). There was no difference between the treatment groups $.64(\mathrm{p}=.43)$. The perphenazine group had an FEDT least-square mean change score of $.13(\mathrm{p}=.66)$ while the group receiving ziprasidone had a least-square mean change score of $-.23(\mathrm{p}=.50)$.

We then examined change in the FEDT in the ziprasidone group relative to the three other atypical medication groups in patients with TD (Data Set IV). There was no overall difference among the treatment groups ( $\mathrm{p}=.77$ ). FEDT least-square mean change scores were not different than zero for patients receiving olanzapine, $0.44(\mathrm{p}=.13)$, quetiapine, $0.37(\mathrm{p}=.18)$, risperidone, $0.47(\mathrm{p}=.11)$, and ziprasidone, $0.07(\mathrm{p}=.81)$.

Effect sizes were small for all treatment groups in all four Data Sets and ranged from .04 to . 18. The pattern in findings, specifically the overlap in confidence intervals, shows that changes 
in emotion perception were relatively equivalent across medications (and for all data sets) (Figure 1).

\subsection{Predictors of emotion perception improvement}

Baseline FEDT score was mildly correlated with most of the predictors at both baseline and 2 month follow-up (Table 3). Prediction of improvement in FEDT from baseline to two months was examined using an ANCOVA. Lower baseline FEDT score and higher baseline neurocognitive composite score $(\mathrm{p}<.001)$ were significant predictors of greater improvement in emotion perception; fewer years on antipsychotic medication was a weak predictor $(\mathrm{p}=0.06)$ (see Table 4).

\section{Discussion}

This study examined whether second-generation antipsychotic medications would result in greater improvement in emotion perception compared to a first generation antipsychotic medication. The results showed that patients in all treatment groups (with the exception of ziprasidone) showed small, non-significant improvements in emotion perception from baseline to two months. However, there were no differences between the medications on emotion perception change. These findings are consistent with the CATIE results for neurocognition (Keefe et al. 2007a) and psychosocial functioning (Swartz et al. 2007) as well as previous research showing limited medication effects on social cognition (Harvey et al. 2006; Sergi et al. 2007). We also found that improvement in emotion perception was significantly associated with lower baseline emotion perception and better neurocognition.

The effect of newer-generation, "atypical" antipsychotic medications on neurocognition in patients with schizophrenia has been controversial (the impact of atypicals on social cognition is a newer area). While many studies and meta-analyses (Harvey and Keefe 2001; Keefe et al. 1999; Woodward et al. 2005) have suggested that second-generation antipsychotic treatment provides greater neurocognitive benefit to schizophrenia patients than first-generation, "typical" antipsychotics, many of these studies have had substantial methodological weaknesses. Analyses of the effects of antipsychotic medications on cognition in the CATIE trial suggested that there were no differences between the atypical medications and the representative medication perphenazine (Keefe et al. 2007a). The magnitude of the performance improvements demonstrated in this trial and others have been interpreted as consistent with practice effects (Keefe et al. 2007a; Keefe et al. 2007b; Nuechterlein et al. 2008). Although practice effects cannot be ruled out in the present study due to the absence of a control or placebo groups, repeated assessment on emotion perception tests does not typically correspond to task improvement (Penn and Combs 2000). This underscores the need to design studies that will clearly identify whether improvements in emotion perception, even small ones, are due to practice effects or treatment.

Better neurocognitive functioning at baseline (as well as poorer emotion perception) was associated with improvement in emotion perception at two months. These findings are congruent with a growing applied research base which shows that improving neurocognition (via psychosocial interventions) may result in improved functioning in more molar domains, such as social cognition, and social and work functioning (McGurk and Mueser 2006; McGurk and Mueser 2004; McGurk et al. 2005; Silverstein et al. 2005; Silverstein et al. 2006; Wexler and Bell 2005). Therefore, better neurocognition may provide traction for improvement in emotion perception (and other more molar functional outcomes) to occur.

In closing, the results suggest that antipsychotic medications have a small, non-statistically significant impact on emotion perception. Interpretation of these results needs to be tempered, as the FEDT is only a single measure of emotion perception, and other domains, such as 
emotion identification, were not assessed. And the absence of a placebo control group prevents confident conclusions that the any improvements (albeit small) were due specifically to the medications. In addition, administration of the FEDT was modified to meet the needs of a large multi-site battery (such as the exposure time of the stimuli), which might have changed it is psychometric properties and contributed to the negative skew of the baseline data (as 59\% of the sample scored 25 or higher on the FEDT at baseline; Table 1). This, in turn, may have attenuated the effects of treatment due to the easiness of the test (although performance on the FEDT by participants in this study was comparable to other research using this measure) (Pinkham and Penn 2006). Thus, it appears that other strategies, such as psychosocial approaches targeting social cognition (reviewed in Horan et al. 2008), need to be utilized to improve emotion perception in schizophrenia.

\title{
Acknowledgments
}

\author{
Acknowledgments \\ None \\ Role of the Funding Source \\ This article was based on results from the Clinical Antipsychotic Trials of Intervention Effectiveness (CATIE) project, \\ supported by the National Institute of Mental Health (NO1 MH-90001). Medications for the study were provided by \\ AstraZeneca Pharmaceuticals L.P., Bristol-Myers Squibb Company, Eli Lilly and Company, Forest Pharmaceuticals, \\ Inc., Janssen Pharmaceutica Products, L.P., Otsuka Pharmaceutical Co., Ltd., Pfizer, Inc., and Zenith Goldline \\ Pharmaceuticals, Inc.
}

\section{References}

Adolphs R. The neurobiology of social cognition. Curr Opin Neurobiol 2001;11(2):231-239. [PubMed: 11301245]

Brothers L. The social brain: a project for integrating primate behavior and neurophysiology in a new domain. Concepts in Neurosci 1990;1:27-61.

Couture SM, Penn DL, Roberts DL. The Functional Significance of Social Cognition in Schizophrenia: A Review. Schizophr Bull 2006;32:S44-s63. [PubMed: 16916889]

Davis SM, Koch GG, Davis CE, LaVange LM. Statistical Approaches to Effectiveness Measurement and Outcome-Driven Re-Randomizations in the Clinical Antipsychotic Trials of Intervention Effectiveness (CATIE) Studies. Schizophr Bull 2003;29(1):73-80. [PubMed: 12908662]

Edwards J, Jackson HJ, Pattison PE. Emotion recognition via facial expression and affective prosody in schizophrenia: A methodological review. Clin Psychol Rev 2002;22(6):789-832. [PubMed: 12214327]

First, M.; Spitzer, R.; Gibbon, M.; Williams, J. Structured Clinical Interview for DSM-IV Axis I Disorders-Administration booklet. American Psychiatric Press Inc; Washington, DC: 1994.

Harvey PD, Keefe RSE. Studies of cognitive change in patients with schizophrenia following novel antipsychotic treatment. Am J Psychiatry 2001;158(2):176-184. [PubMed: 11156796]

Harvey PD, Patterson TL, Potter LS, Zhong K, Brecher M. Improvement in social competence with shortterm atypical antipsychotic treatment: A randomized, double-blind comparison of quetiapine versus risperidone for social competence, social cognition, and neuropsychological functioning. Am J Psychiatry 2006;163(11):1918-1925. [PubMed: 17074943]

Hellewell, JSE.; Whittaker, JF.; Mueser, KT.; Tarrier, N. Affect perception and social knowledge in schizophrenia. In: Mueser, KT.; Tarrier, N., editors. Handbook of social functioning in schizophrenia. Allyn \& Bacon; Needham Heights, MA US: 1998. p. 197-212.

Herbener ES, Hill SK, Marvin RW, Sweeney JA. Effects of Antipsychotic Treatment on Emotion Perception Deficits in First-Episode Schizophrenia. Am J Psychiatry 2005;162(9):1746-1748. [PubMed: 16135639]

Horan WP, Kern RS, Green MF, Penn DL. Social cognition training for individuals with schizophrenia: Emerging evidence. Am J Psychiatr Rehabil 2008;11(3):205-252. 
Kee KS, Kern RS, Marshall BD Jr, Green MF. Risperidone versus haloperidol for perception of emotion in treatment-resistant schizophrenia: Preliminary findings. Schizophr Res 1998;31(2):159-165. [PubMed: 9689720]

Keefe RSE, Bilder RM, Davis SM, Harvey PD, Palmer BW, Gold JM, Meltzer HY, Green MF, Capuano G, Stroup TS, et al. Neurocognitive effects of antipsychotic medications in patients with chronic schizophrenia in the CATIE trial. Arch Gen Psychiatry 2007a;64(6):633-647. [PubMed: 17548746]

Keefe RSE, Bilder RM, Harvey PD, Palmer BW, Meltzer HY, Miller DD, Adler LW, Swartz M, Perkins DO, Lieberman JA, et al. Baseline Neurocognitive Deficits in the CATIE Schizophrenia Trial. Neuropsychopharmacol 2006;31(9):2033-2046.

Keefe RSE, Malhotra AK, Meltzer HY, Kane JM, Buchanan RW, Murthy A, Sovel M, Li C, Goldman R. Efficacy and Safety of Donepezil in Patients with Schizophrenia or Schizoaffective Disorder: Significant Placebo//Practice Effects in a 12-Week, Randomized, Double-Blind, Placebo-Controlled Trial. Neuropsychopharmacol 2007b;33(6):1217-1228.

Keefe RSE, Mohs RC, Bilder RM, Harvey PD, Green MF, Meltzer HY, Gold JM, Sano M. Neurocognitive Assessment in the Clinical Antipsychotic Trials of Intervention Effectiveness (CATIE) Project Schizophrenia Trial: Development, Methodology, and Rationale. Schizophr Bull 2003;29(1):45-55. [PubMed: 12908660]

Keefe RSE, Silva SG, Perkins DO, Lieberman JA. The effects of atypical antipsychotic drugs on neurocognitive impairment in schizophrenia: A review and meta-analysis. Schizophr Bull 1999;25 (2):201-222. [PubMed: 10416727]

Kerr SL, Neale JM. Emotion perception in schizophrenia: Specific deficit or further evidence of generalized poor performance? J Abnorm Psychol 1993;102(2):312-318. [PubMed: 8315144]

Kohler CG, Brennan AR. Recognition of facial emotions in schizophrenia. Curr Opin Psychiatry 2004;17 (2):81-86.

Lieberman JA, Stroup TS, McEvoy JP, Swartz MS, Rosenheck RA, Perkins DO, Keefe RSE, Davis SM, Davis CE, Lebowitz BD, et al. Effectiveness of Antipsychotic Drugs in Patients with Chronic Schizophrenia. N Engl J Med 2005;353(12):1209-1223. [PubMed: 16172203]

Littrell KH, Petty RG, Hilligoss NM, Kirshner CD, Johnson CG. Improvement in social cognition in patients with schizophrenia associated with treatment with olanzapine. Schizophr Res 2004;66(2): 201-202. [PubMed: 15061258]

Mandal MK, Pandey R, Prasad AB. Facial expressions of emotions and schizophrenia: A review. Schizophr Bull 1998;24(3):399-412. [PubMed: 9718632]

McGurk SR, Mueser KiT. Strategies for coping with cognitive impairments of clients in supported employment. Psychiatr Serv 2006;57(10):1421-1429. [PubMed: 17035559]

McGurk SR, Mueser KT. Cognitive functioning, symptoms, and work in supported employment: A review and heuristic model. Schizophr Res 2004;70(2):147-173. [PubMed: 15329293]

McGurk SR, Mueser KT, Pascaris A. Cognitive training and supported employment for persons With severe mental illness: One-year results from a randomized controlled trial. Schizophr Bull 2005;31 (4):898-909. [PubMed: 16079391]

Nuechterlein KH, Green MF, Kern RS, Baade LE, Barch DM, Cohen JD, Essock S, Fenton WS, Frese FJ III, Gold JM, et al. The MATRICS consensus cognitive battery, part 1: Test selection, reliability, and validity. Am J Psychiatry 2008;165(2):203-213. [PubMed: 18172019]

Penn, DL.; Addington, J.; Pinkham, A.; Lieberman, JA.; Stroup, TS.; Perkins, DO. The American Psychiatric Publishing Textbook of Schizophrenia. American Psychiatric Publishing, Inc; Arlington, VA US: 2006. Social Cognitive Impairments; p. 261-274.

Penn DL, Combs D. Modification of affect perception deficits in schizophrenia. Schizophrenia Research 2000;46(2):217-229. [PubMed: 11120434]

Penn DL, Corrigan PW, Bentall RP, Racenstein JM, Newman L. Social cognition in schizophrenia. Psychol Bull 1997;121(1):114-132. [PubMed: 9000894]

Pinkham AE, Penn DL. Neurocognitive and social cognitive predictors of interpersonal skill in schizophrenia. Psychiatry Res 2006;143(2):167-178. [PubMed: 16859754]

Sergi MJ, Green MF, Widmark C, Reist C, Erhart S, Braff DL, Kee KS, Marder SR, Mintz J. Cognition and neurocognition: Effects of risperidone, olanzapine, and haloperidol. Am J Psychiatry 2007;164 (10):1585-1592. [PubMed: 17898351] 
Silverstein SM, Hatashita-Wong M, Solak BA, Uhlhaas P, Landa Y, Wilkniss SM, Goicochea C, Carpiniello K, Schenkel LS, Savitz A, et al. Effectiveness of a two-phase cognitive rehabilitation intervention for severely impaired schizophrenia patients. Psychol Med 2005;35(6):829-837. [PubMed: 15997603]

Silverstein SM, Hatashita-Wong M, Wilkniss S, Bloch A, Smith T, Savitz A, McCarthy R, Friedman M, Terkelsen K. Behavioral rehabilitation of the 'treatment-refractory' schizophrenia patient: Conceptual foundations, interventions, and outcome data. Psychol Serv 2006;3(3):145-169.

Stroup TS, McEvoy JP, Swartz MS, Byerly MJ, Glick ID, Canive JM, McGee MF, Simpson GM, Stevens MC, Lieberman JA. The National Institute of Mental Health Clinical Antipsychotic Trials of Intervention Effectiveness (CATIE) Project: Schizophrenia Trial Design and Protocol Development. Schizophr Bull 2003;29(1):15-31. [PubMed: 12908658]

Swartz MS, Perkins DO, Stroup TS, Davis SM, Capuano G, Rosenheck RA, Reimherr F, McGee MF, Keefe RSE, McEvoy JP, et al. Effects of antipsychotic medications on psychosocial functioning in patients with chronic schizophrenia: Findings from the NIMH CATIE Study. Am J Psychiatry 2007;164(3):428-436. [PubMed: 17329467]

Wexler BE, Bell MD. Cognitive remediation and vocational rehabilitation for schizophrenia. Schizophr Bull 2005;31(4):931-941. [PubMed: 16079390]

Woodward ND, Purdon SE, Meltzer HY, Zald DH. A meta-analysis of neuropsychological change to clozapine, olanzapine, quetiapine, and risperidone in schizophrenia. Int J Neuropsychopharm 2005;8 (03):457-472. 


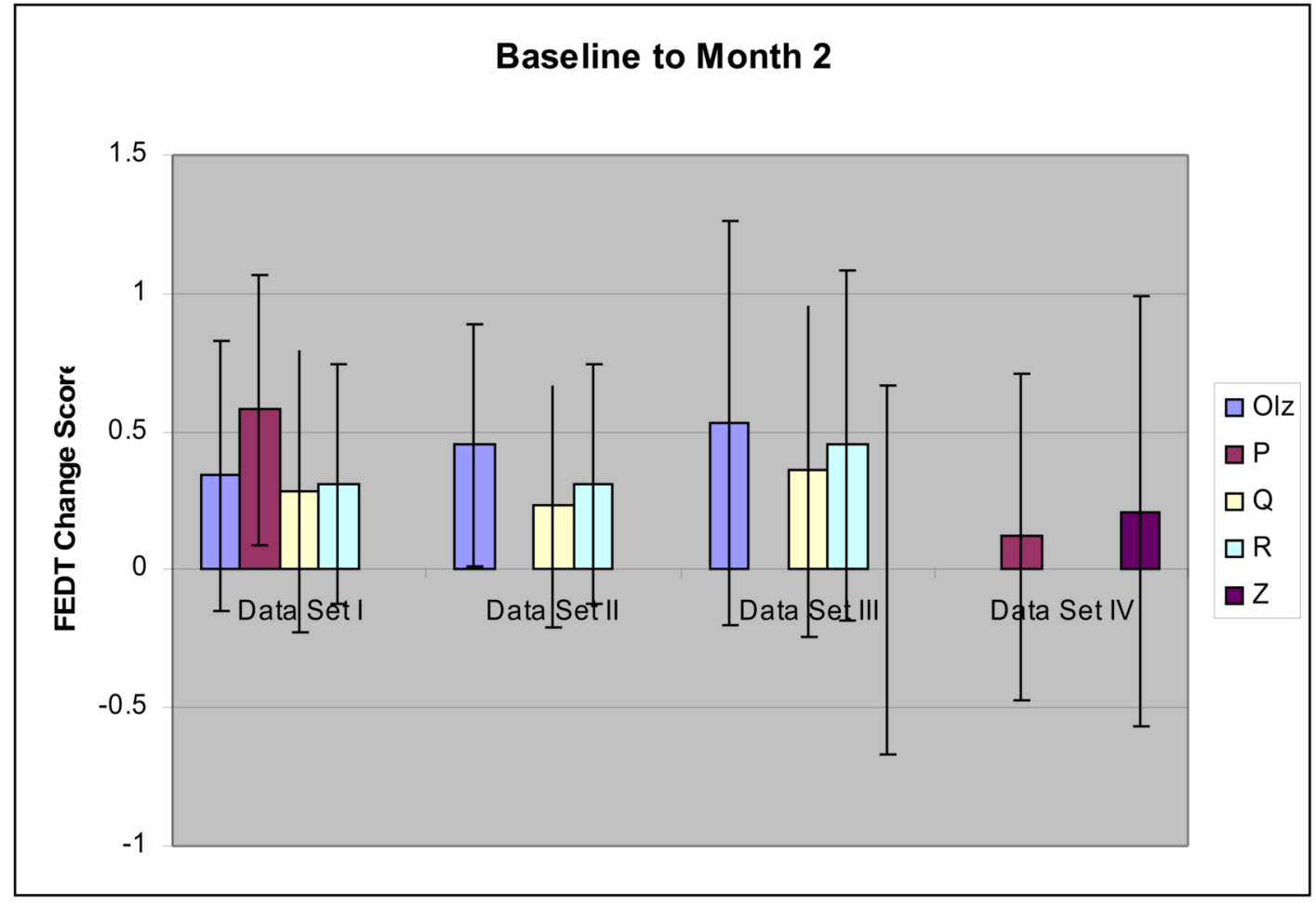

Figure 1.

Mean FEDT Baseline to Month 2 Change Scores for Data Sets I, II, III, and IV with 95\% confidence intervals

Note: $\mathrm{Olz}=$ Olanzapine; $\mathrm{P}=$ Perphenazine; $\mathrm{Q}=$ Quetiapine; $\mathrm{R}=$ Risperidone $\mathrm{Z}=$ Ziprasidone 
Table 1

Demographic and Baseline Characteristics of Patients with FEDT Data

\begin{tabular}{|c|c|c|c|c|}
\hline \multirow{2}{*}{ Variable } & \multirow{2}{*}{$\begin{array}{l}\text { BL Data and Month } 2 \text { Data } \\
\text { Available }(\mathbf{N}=873) \\
\text { Mean(SD) or N(\%) } \\
40.96(10.91)\end{array}$} & \multicolumn{3}{|c|}{$\begin{array}{l}\text { BL Data Available but Month } 2 \mathrm{P} \text {-value for comparing patients with Month } 2 \\
\begin{array}{ll}\text { Data Not Available (N=515) } & \begin{array}{l}\text { Data vs. without } \\
\text { Tean or Chi-Square statisticp-value }\end{array}\end{array}\end{array}$} \\
\hline & & $39.66(11.30)$ & 2.13 & 0.03 \\
\hline Patient's Education (years) & $12.18(2.20)$ & $12.08(2.25)$ & 0.75 & 0.45 \\
\hline Duration Since First Prescribed & $14.49(10.92)$ & $14.17(10.40)$ & 0.53 & 0.60 \\
\hline $\begin{array}{l}\text { Antipsychotic Medication (years) } \\
\text { PANSS(total score) }\end{array}$ & $74.29(17.48)$ & $77.09(17.27)$ & -2.89 & $<0.001$ \\
\hline Sex & & & & \\
\hline Male & $655(75.03 \%)$ & $380(73.79 \%)$ & 0.26 & 0.61 \\
\hline Female & $218(24.97 \%)$ & $135(26.21 \%)$ & & \\
\hline Race & & & & \\
\hline White & $534(61.24 \%)$ & $302(58.75 \%)$ & 0.86 & 0.35 \\
\hline Other & $338(38.76 \%)$ & $212(41.24 \%)$ & & \\
\hline Ethnic Origin & & & & \\
\hline $\begin{array}{l}\text { Hispanic } \\
\text { Baseline Antipsychotic Medications }\end{array}$ & $95(10.88 \%)$ & $158(30.68 \%)$ & 0.05 & 0.83 \\
\hline $\begin{array}{l}\text { Olanzapine alone } \\
\text { Olo }\end{array}$ & $213(24.40 \%)$ & $99(19.22 \%)$ & 4.98 & 0.03 \\
\hline Quetiapine alone & $54(6.19 \%)$ & $36(6.99 \%)$ & 0.35 & 0.56 \\
\hline Risperidone alone & $183(20.96 \%)$ & $83(16.12 \%)$ & 4.90 & 0.03 \\
\hline $\begin{array}{l}\text { Any combination which includes } \\
\text { olanzapine, quetiapine, or risperidone }\end{array}$ & $72(8.25 \%)$ & $52(10.10 \%)$ & 1.36 & 0.24 \\
\hline All others & $130(14.89 \%)$ & $87(16.89 \%)$ & 0.98 & 0.32 \\
\hline None & $221(25.32 \%)$ & $158(30.68 \%)$ & 4.70 & 0.03 \\
\hline Baseline FEDT & $24.58(3.40)$ & $24.19(3.53)$ & 0.43 & 0.67 \\
\hline Median Baseline FEDT & 25.00 & & & \\
\hline Frequency Baseline FEDT (for BL and & $\mathrm{d}<20 \mathrm{~N}(\%)$ & $20-24 \mathrm{~N}(\%)$ & $25-28 \mathrm{~N}(\%)$ & $29-30 \mathrm{~N}(\%)$ \\
\hline Month 2 Data) & & & & \\
\hline & $60(6.87 \%)$ & $298(34.14 \%)$ & $460(52.69 \%)$ & $55(6.30 \%)$ \\
\hline
\end{tabular}




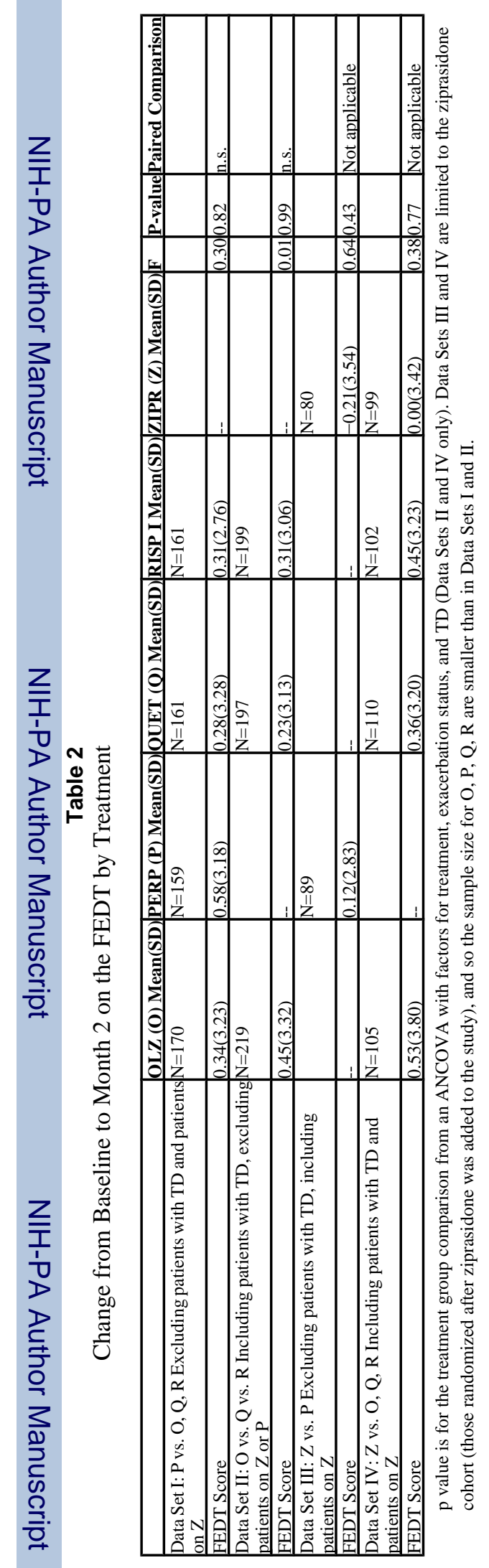


Table 3

Correlation between Predictors and Baseline and 2 month FEDT Scores

\begin{tabular}{|c|c|c|}
\hline & Baseline FEDT & 2 month FEDT \\
\hline Number of Years of Patient's Education & $.13^{* *}$ & $.16^{* *}$ \\
\hline Years Since First Prescribed an Antipsychotic Medication & $-.16^{* *}$ & $-.19^{* *}$ \\
\hline Baseline Neurocognitive Composite Score & $.32^{* *}$ & $.34^{* *}$ \\
\hline Reading Subtest of the WRAT & $.25^{* *}$ & $.26^{* *}$ \\
\hline Baseline QOL Interpersonal Relations & $.10^{* *}$ & .06 \\
\hline Baseline PANSS Negative Scale & $-.16^{* *}$ & $-.14^{* *}$ \\
\hline Baseline PANSS Positive Scale & $-.086^{* *}$ & -.03 \\
\hline Gender (t-test) & $\mathrm{t}=2.03, \mathrm{p}=.03$ & $\mathrm{t}=3.80, \mathrm{p}<.01$ \\
\hline Alcohol Status (ANOVA) & $\mathrm{F}=0.52, \mathrm{p}=.59$ & $\mathrm{~F}=.21, \mathrm{p}=.81$ \\
\hline
\end{tabular}

Note: $\mathrm{p}<.05$,

** $\mathrm{p}<.01$ 
Table 4

Prediction of change in FEDT performance at two months from baseline variables

\begin{tabular}{|c|c|c|c|c|}
\hline Variable & Regression Coefficient & Standard Error & t-value & p-value \\
\hline Baseline FEDT score & -0.50 & 0.03 & -14.47 & $<.0001$ \\
\hline Gender $(1=$ male, $2=$ female $)$ & 0.44 & 0.25 & 1.73 & 0.08 \\
\hline Number of Years of Patient's Education & 0.06 & 0.06 & 1.17 & 0.24 \\
\hline Years Since First Prescribed an & -0.02 & 0.01 & -1.88 & 0.06 \\
\hline Antipsychotic Medication & & & & \\
\hline $\begin{array}{l}\text { Alcohol Status ( } 0=\text { abstinence, } 1=\text { use, } \\
2=\text { abuse })\end{array}$ & 0.21 & 0.13 & 1.64 & 0.10 \\
\hline Baseline Neurocognitive Composite Score & 0.45 & 0.13 & 3.36 & $<.001$ \\
\hline Reading Subtest of the WRAT & 0.02 & 0.01 & 1.49 & 0.14 \\
\hline Baseline QOL Interpersonal Relations & -0.06 & 0.09 & -0.77 & 0.44 \\
\hline Baseline PANSS Negative Scale & 0.01 & 0.02 & 0.23 & 0.82 \\
\hline Baseline PANSS Positive Scale & -0.01 & 0.02 & -0.64 & 0.52 \\
\hline $\begin{array}{l}\text { Requiring crisis stabilization in the } 3 \\
\text { months prior to study entry (exacerbation } \\
\text { status) }\end{array}$ & -0.05 & 0.24 & -0.22 & 0.82 \\
\hline $\begin{array}{l}\text { Investigator site, pooled into } 6 \text { groups based } \\
\text { on site care setting }\end{array}$ & -- & -- & -- & 0.27 \\
\hline
\end{tabular}

Note: All of the above variables were entered simultaneously. Model $\mathrm{R}^{2}=0.31$ 